\title{
A REPRESENTAÇÃO ÉTNICO-RACIAL NOS CADERNOS DE CIÊNCIAS DA NATUREZA DAS REDES MUNICIPAL E ESTADUAL DE SÃO PAULO ${ }^{1}$
}

Caio Ricardo Faiad da Silva ${ }^{2}$ Gabriela Aparecida de Lima ${ }^{3}$ Daisy de Brito Rezende 4

Resumo: A premissa da educação para a equidade racial ganhou reforço legislativo com a obrigatoriedade do ensino de história e culturas africanas, afro-brasileiras e indígenas, por meio das leis 10639/2003 e 11645/2008. Já as pesquisas em Educação têm apontado a enorme importância que o material didático exerce no ambiente escolar. Nesse sentido, o objetivo deste artigo é analisar a representatividade e a representação étnico-racial em duas coleções elaboradas e distribuídas para as redes municipal e estadual de São Paulo. Conclui-se que, nas coleções estudadas, os negros estão sub-representados nas imagens enquanto a presença de brancos é prevalente. Além disso, quando se representa o ser humano dotado de intelectualidade, a referência é a de brancos. Dessa forma, busca-se chamar a atenção da comunidade para o reconhecimento e a reversão dessa realidade brasileira.

Palavras-chave: material didático, equidade racial, ensino de Ciências

\footnotetext{
${ }^{1}$ Versão preliminar deste texto foi apresentado no XII Encontro Nacional de Pesquisa em Educação em Ciências realizado na Universidade Federal do Rio Grande do Norte (UFRN) de 25 a 28 de junho de 2019.

2 Doutorando em Ensino de Ciências -PIEC/USP. Bacharel em Química Ambiental - IBILCE/UNESP, Especialista em Planejamento, Implementação e Gestão da EaD - Lante-UFF. Mestre em Química IQ/UNICAMP. Bacharel e Licenciado em Letras - Português - FFLCH/USP. E-mail: profcaiofaiad@gmail.com

${ }^{3}$ Licenciada em Química (IQ/USP) com iniciação científica na área de Educação Científica. Estagiária de Química na Escola Viva. Bolsista do projeto Negritude na Escola de Aplicação FEUSP. Email: gablima03@gmail.com

${ }^{4}$ Docente do Departamento de Química Fundamental, Instituto de Química da USP. Licenciada e bacharela em Química pela USP, mestre e doutora em Química Orgânica pela USP. E-mail: dbrezend@iq.usp.br
} 


\begin{abstract}
The premise of racial equity in education has gained legislative reinforcement with the compulsory teaching of African, Afro-Brazilian and indigenous history and culture through laws 10639/2003 and 11645/2008. Some studies have pointed out a huge importance to the textbooks in the school environment. In this sense, the objective of this article is to analyze the ethnic-racial representativeness and representation in two school textbooks collections distributed in the City and State of São Paulo. In the studied collections, blacks are underrepresented in the images while the presence of whites is prevalent. Moreover, the people enrolled in more intellectual affairs are refered to, the reference is to white people. Thus, we seek to draw the community's attention to the recognition and reversal of this Brazilian reality.
\end{abstract}

Keywords: school textbooks, racial equality, science teaching

\title{
LA REPRESENTACIÓN ÉTNICO-RACIAL EN LOS CUADERNOS DE CIENCIAS NATURALES DISTRIBUIDOS EN LAS ESCUELAS DE LAS REDES MUNICIPALES Y ESTATALES DE SÃO PAULO
}

Resumen: La premisa de la educación en equidad racial ha ganado un refuerzo legislativo con la obligación de enseñar la historia y las culturas africanas, afrobrasileñas e indígenas a través de las leyes 10639/2003 y 11645/2008. Por otro lado, la investigación en Educación ha señalado la enorme importancia que tiene el material didáctico en el entorno escolar. En este sentido, el objetivo de esta investigación es analizar la representatividad y la representación étnico-racial en dos colecciones elaboradas y distribuidas a las redes municipales y estatales de São Paulo. Se concluye que, en las colecciones estudiadas, los negros están subrepresentados en las imágenes, mientras que la presencia de blancos es prevalente. Además, cuando se representa al ser humano dotado de intelectualidad, la referencia es la de los blancos. Por lo tanto, buscamos llamar la atención de la comunidad sobre el reconocimiento y la reversión de esta realidad brasileña.

Palabras-clave: materiales didácticos, equidad racial, educación científica

\section{LA REPRESENTATION ETHNIQUE-RACIALE SUR LES CAHIERS DE SCIENCES NATURELLES DISTRIBUÉES AUX LYCÉES PUBLIQUES DE SÃO PAULO}

Résumé: La premisse d'utiliser l'éducation comme un moyen d'atteindre l'équité raciale a été renforcé par la législation brésilienne, dont a obligée l'enseignement de l'histoire et des cultures africaines, afro-brésiliennes et indigènes avec les lois 10639/2003 et 11645/2008. Pourtant, les recherches en éducation ont mis en évidence la grande importance du matériel 
didactique sur l'environnement scolaire. Ainsi, l'objectif de cette étude a été l'analyse de la représentativité et la représentation ethno-raciale de deux collections élaborées et distribuées aux lycées publiques de São Paulo. L'analyse a conclu que les noirs sont sous-représentés dans les images alors que la présence des blancs est prédominante. En ajoutant, quand un humain est réprésenté comme intellectuel, la préférence de représentation est aussi blanc. Donc, l'étude attire l'attention de la communauté scientifique sur la reconnaissance et la renversement de cette réalité brésilienne.

Mots-clés: matériel pédagogique, équité raciale, enseignement des sciences

\section{INTRODUÇÃO}

No estado de São Paulo, em 2008, com a implementação da nova Proposta Curricular, chegou às escolas um novo material para auxiliar as práticas pedagógicas do professor e contribuir para a aprendizagem dos alunos: o caderno do professor e o caderno do aluno (São Paulo, 2009). Segundo Maia e Villani (2016, p. 143) apesar das queixas dos professores, a adoção do novo material provocou um avanço na organização das aulas de alguns professores, contribuindo para sua autonomia no exercício de suas práticas pedagógicas. Em 2018, o município de São Paulo seguiu passos análogos aos do Estado ao implementar o Currículo da Cidade e adotar os "Cadernos da Cidade - Saberes e Aprendizagem” (São Paulo, 2018).

Ao inserir a obrigatoriedade do ensino de história e culturas africanas, afro-brasileiras e indígenas, as leis 10639/2003 e 11645/2008 (Brasil, 2008) trouxeram para a educação brasileira, no âmbito legal, a perspectiva de uma educação para a equidade racial. Embora essas políticas voltem-se à população negra e indígena brasileiras, vale ressaltar que vários teóricos brasileiros sempre apontaram para uma nação plurirracial. Munanga e Gomes (2016, p. 17-8), por exemplo, reforçam a ideia de que, sendo a contribuição para a formação da sociedade brasileira oriunda de quatro continentes América, Europa, África e Ásia, “aprender a conhecer o Brasil é aprender a conhecer a história e a cultura de cada um desses componentes para melhor captar sua contribuição na cultura e na história do país."

Entendendo que o material didático deve acompanhar o discurso e as práticas 
pedagógicas que contemplem a diversidade étnico-cultural, o presente trabalho se propõe a indagar e refletir sobre a representatividade e representação étnico-racial veiculada por meio de diferentes tipos de imagens nesses novos materiais didáticos elaborados pelo Poder Público para serem adotados no Ensino Fundamental, onde ocorre o primeiro contato com o aprendizado sobre as Ciências da Natureza. A presente pesquisa se justifica pela explicitação de abordagens diversificadas que possibilitam a sustentação de práticas pluralistas e que englobem a diversidade étnico-racial do povo brasileiro.

\section{A QUESTÃO DAS REPRESENTAÇÕES ÉTNICO-RACIAIS NOS MATERIAIS DIDÁTICOS}

Várias pesquisas em Educação (Lajolo, 1996; Corrêa, 2000; Megid Neto; Fracalanza, 2003) têm apontado a enorme importância que o material didático exerce no ambiente escolar. Um dos pontos-chave da administração educacional brasileira é o programa de distribuição de livros didáticos, que, além de ampliar o acesso a esses materiais, objetiva elevar sua qualidade. Essa qualidade, no entanto, é analisada e intensamente questionada nas pesquisas em Educação, visto que "o livro didático exerce o papel, especificamente junto aos alunos das classes populares, de ser, muitas vezes, o único recurso de leitura informativa, formativa e lúdica" (Silva, 1999, p. 1). Portanto, além da intensa averiguação de conteúdo e dos mecanismos didáticos na explanação de conceitos, pesquisas de caráter sociológico passaram a problematizar o papel do material didático na construção das representações, pelos alunos, acerca de vários objetos sociais presente no material didático.

Durkheim (2004 apud Teixeira, 2011, p. 2643) argumenta que "toda representação, no momento onde ela se produz, afeta, além dos órgãos, o próprio espírito, as representações passadas e presentes subsistem em nós. Elas podem agir de forma positiva ou negativa.” Já para Moscovici (2004 apud Teixeira, 2011, p. 2654), “as representações sustentadas pela comunicação constituem as realidades de nossa vida cotidiana e servem como o principal meio para estabelecer as associações com as quais nós nos ligamos uns aos outros."

É durante a aprendizagem escolar que o aluno entra em contato com concepções de 
mundo que orientam seu posicionamento, assim como, o ajudam no processo de construção de sua própria identidade. Sendo a educação um aspecto vital na luta contra o preconceito racial e o espaço escolar responsável por boa parte da formação do indivíduo, o ambiente escolar se torna importante para a suplantação de desigualdades raciais e do racismo.

Nesse sentido, as investigações sobre as representações sociais em materiais didáticos vêm se expandindo na literatura acadêmica. A maioria das pesquisas, no entanto, é realizada tendo os livros didáticos de Língua Portuguesa e História como corpus de análise (Ribeiro, 2010; Silva, 2011; Matte Júnior, Alves, Gevehr, 2017). Embora, no campo étnico-racial, a maior parte das pesquisas vise estudar as representações de negros nos livros didáticos, há trabalhos em que o foco principal é a representação de pessoas brancas e os efeitos de sentido que essa representação produz (Teixeira, 2011). Em outros, o objeto de investigação é o espaço em que se inserem os indivíduos nas imagens que ilustram os livros didáticos de Geografia (Santos, 2013), ao invés de analisarem-se os indivíduos em si.

Contudo, embora trabalhos com esse enfoque ainda sejam incipientes no campo da pesquisa em Ensino de Ciências da Natureza, podem-se destacar as pesquisas de Lopes (2016) e Silvério (2016) que, para além de apontarem a falta de representatividade de corpos não-brancos nos livros didáticos, destacam criticamente as problemáticas acerca de suas poucas aparições. Para Silvério (2016), a predominância de corpos brancos nas representações de anatomia humana nos livros de Biologia corrobora e legitima o imaginário social do branco como ser humano universal enquanto outros grupos são colocados na fronteira do humano e não-humano. Já Lopes (2016) salienta que a falta de representatividade negra nos livros didáticos de Ciências da Natureza sustenta a narrativa racista de uma pouca, ou ainda, nenhuma participação do povo negro na história e cultura brasileiras.

\section{PROCEDIMENTOS METODOLÓGICOS}

Como corpus de análise foram selecionadas duas coleções didáticas elaboradas e distribuídas para as redes públicas do município de São Paulo e do Estado paulista. As coleções serão denominadas, ao longo do texto, como coleção A e coleção B. A coleção A 
se refere ao Caderno do Aluno distribuído, a partir de 2009, na rede pública estadual de São Paulo e, a coleção B, se refere ao Caderno da Cidade, distribuído, a partir de 2018, na Rede Pública Municipal de São Paulo. A coleção A é dividida em 4 volumes (um por bimestre), totalizando 16 cadernos analisados. Já a coleção B é dividida em 2 volumes (um por semestre), totalizando a análise em 8 cadernos.

Para este trabalho, foram analisadas as imagens presentes nas coleções A e B que apresentam a figura humana nas suas mais variadas formas. Essas imagens foram tratadas considerando-se alguns aspectos da análise de conteúdo na perspectiva de Bardin (1977) para a construção das categorias de análise. Nesta perspectiva, a análise de conteúdo constitui-se em um conjunto de técnicas que buscam a descrição e interpretação de mensagens presentes em um determinado material. Embora essas técnicas não sejam rígidas, de modo geral, seguem as seguintes etapas: pré-análise, exploração do material e tratamento dos resultados, a inferência e a interpretação.

As diferentes formas de representação humana presentes nas coleções foram classificadas em termos de etnia/raça. Assim como Silvério (2016), para fins de análise, foram consideradas como representações humanas: o corpo humano completo, a parte superior do indivíduo, os membros inferiores e superiores, o tórax, o abdômen, os genitais e a cabeça. Ainda seguindo Silvério (2016), não foram consideradas as representações que auxiliam na descrição de patologias, pois, neste artigo, adotou-se o recorte de que a representação da doença, do disfuncional, do patológico, do aberrante consiste em outra discussão, tão relevante quanto a que está sendo apresentada neste momento

Para a atribuição de etnia/raça foram considerados os pressupostos da heteroidentificação, isto é, da identificação, por terceiros, da etnia/raça de um determinado indivíduo. Ainda no que tange à aferição de etnia/raça, quando a identidade não foi mencionada no texto, levaram-se em consideração características fenotípicas que são determinantes na identificação racial como cor da pele, cabelo e traços faciais. Nas representações em que o rosto pode ser identificado, foi adotado o sistema classificatório de cor/raça do IBGE, que consiste em seis opções: branco, amarelo, indígena, preto, pardo e outro. Contudo, como preto e pardo podem formar uma única categoria denominada negro, 
esta foi a nomenclatura entendimento adotada neste trabalho. Nas representações em que não é possível ver o rosto, adotou-se a classificação branca ou negra.

Vale ressaltar que o presente trabalho foi realizado com apoio da Coordenação de Aperfeiçoamento de Pessoal de Nível Superior - Brasil (CAPES) - Código de Financiamento 001.

\section{RESULTADOS E DISCUSSÃO}

Ao todo, foram identificadas 61 imagens com representação humana na coleção A e 148 imagens na coleção B. Destas, foram excluídas aquelas em que não era possível a identificação étnico-racial, ora por apresentarem apenas a silhueta humana (FIGURA 1A) ora por aparecer o corpo humano todo coberto (FIGURA 1B). Há, ainda, imagens em que um determinado sujeito aparece repetitivamente (FIGURA 1C), caso em que a representação foi contabilizada uma única vez.

Figura 1. Imagens de representação humana não incluídas na análise étnico-racial. A Apenas a silhueta; B - corpo coberto; C - representações de um mesmo sujeito repetidas diversas vezes.

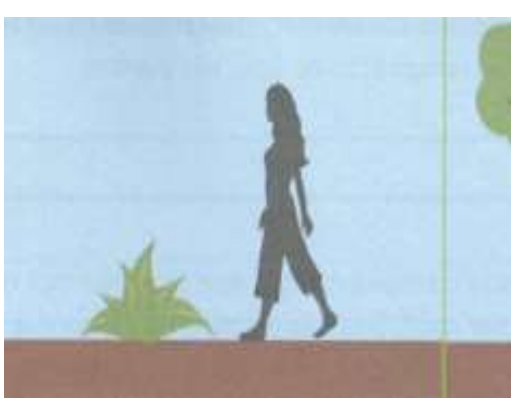

A

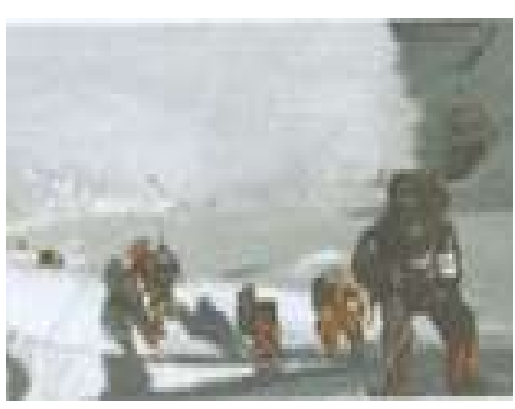

B

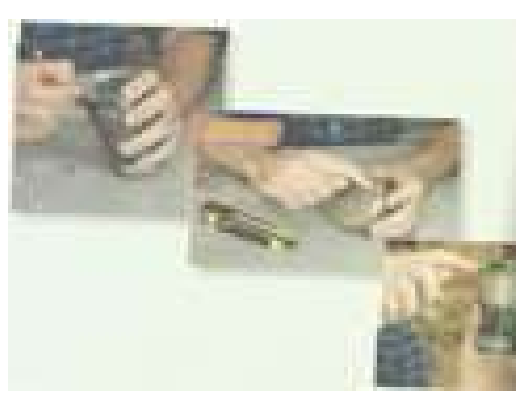

$\mathrm{C}$

Assim, a presente análise foi realizada sob o conjunto de 54 representações da figura

Revista da ABPN • v. 11, Ed. Especial - Caderno Temático: "Saber-fazer em Ciências \& Tecnologias - Trajetórias Afrodiaspóricas" • dezembro de 2019, p. 90-108 
humana em 47 imagens na coleção A e 170 representações humanas, em um total de 100 imagens, da coleção B. Os resultados serão apresentados em duas perspectivas: a representação e a representatividade.

Para Coelho Netto (2003, p. 152), "uma tela, uma escultura, um filme pode perfeitamente ser descritos como mensagens, como grupos de elementos de percepção extraídos de repertórios determinados e com uma estrutura certa". Segundo Maimone e Gracioso (2007, p. 133), a análise de imagens é a tradução, para uma linguagem verbal, do aspecto visual de uma obra, como fotografias, filmes e pinturas. Nesse sentido, o conteúdo da imagem transmite significados, sejam eles explícitos ou não. Para este trabalho, esses significados serão abordados na esfera da representação. Já o conceito de representatividade será vinculado ao aspecto quantitativo, referindo-se, assim, à distribuição étnico-racial das imagens e sua congruência com a distribuição étnico-racial da sociedade.

\section{A REPRESENTATIVIDADE ÉTNICO-RACIAL}

Na Figura 2, é possível observar as seguintes porcentagens sobre a representatividade étnico-racial da coleção A: branca $85,2 \%$ (46 representações), negra $11,1 \%$ (6 representações), indígena 3,7\% (2 representações) e amarela 0,0\% (0 representação). Na coleção B, tem-se: branca 82,9\% (141), negra 10,6\% (18), indígena 4,7\% (8) e amarela 1,8\% (3).

Figura 2. Gráfico da distribuição das imagens pelo critério étnico-racial.



\section{O)}

Muito embora a coleção A tenha sido publicada em 2009 (6 anos após a lei 10.639/2003 e 1 ano após a lei 11,645/2008) e a coleção B, em 2018 (15 anos e 10 anos após as respectivas leis) ambos os materiais ainda apresentam deficiências na representatividade de grupos minoritários, pois observa-se a preponderância de imagens de brancos, em ambos os casos, em mais de $80 \%$ das imagens, constituindo-se claramente em grupo étnico-racial majoritário nos livros analisados, em detrimento dos demais grupos que formam a sociedade brasileira.

Após a seleção de todas as imagens em que seres humanos eram representados, foi verificado que havia três grandes tipos de imagem: retratos, ilustrações e imagens artísticas. $\mathrm{Na}$ categoria Retrato foram enquadradas as imagens que buscam descrever um ser humano existente na realidade; normalmente essas imagens são elaboradas por técnicas fotográficas, mas também há pinturas feitas em um período histórico em que a fotografia ainda não existia. Na segunda categoria, estão as imagens do tipo Ilustração, que se referem aos desenhos criados exclusivamente para o material didático com o objetivo de aproximar os Cadernos à faixa etária do público-alvo. Já a terceira categoria, denominada de Arte, apresenta representações humanas elaboradas para finalidades artísticas, no sentido estrito (Quadro 1).

Quadro 1. Exemplo de imagens por categorias em cada uma das coleções.

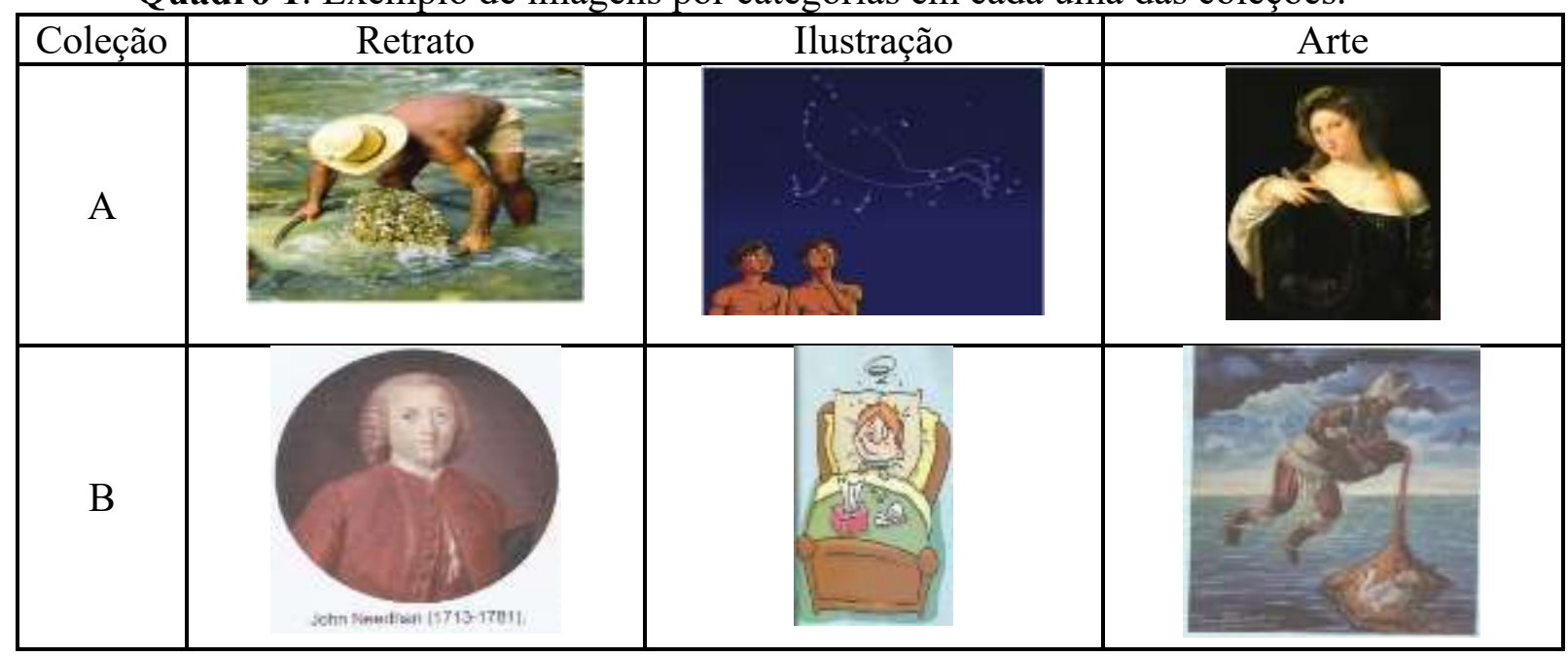


A Figura 3 apresenta a distribuição das categorias de imagens em cada uma das coleções estudadas. Comparando-se a distribuição das categorias das imagens nas coleções A e B, verifica-se que a coleção A dá preferência para imagens do tipo Ilustração, 72,2\% (39) ao todo, contra 22,2\% (12) do tipo Retrato e 5,6\% (3) do tipo Arte. Já a coleção B prioriza as imagens do tipo Retrato, 54,1\% (92) ao todo. Ainda sobre a coleção B, há também o aumento de imagens do tipo Arte 14,1\% (24), além dos 31,8\% (54) do tipo Ilustração.

Figura 3. Gráfico da distribuição das imagens por categoria de imagem.

\section{Coleção A}



Coleção B

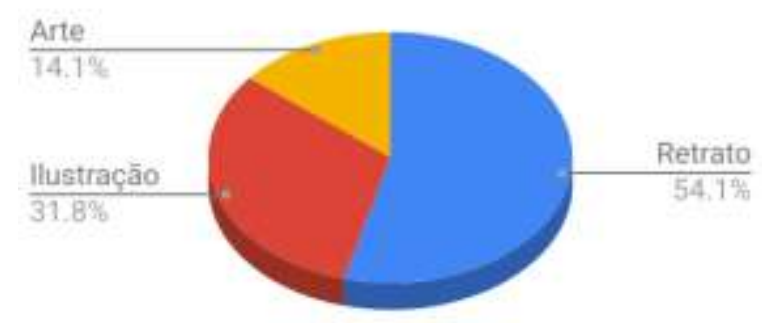

Sendo as imagens do tipo Retrato e Arte provenientes de bancos de imagens e as imagens do tipo Ilustração elaboradas especialmente para as obras, poder-se-ia presumir que os critérios étnico-racial nessa última categoria fossem melhor distribuídos, porque bastaria a orientação dos organizadores do material ao ilustrador para que as imagens criadas para as figuras humanas fossem racialmente mais equânimes.

Os dados da Figura 4, no entanto, mostram que esta hipótese não se sustenta, pois a representatividade de pessoas brancas nas imagens do tipo Ilustração é equivalente às verificadas para imagens do tipo Retrato e Arte. Na análise da Figura 4 observa-se que, para a Coleção A, na categoria Retrato, as imagens de pessoas brancas totalizam 75\%, em Arte 100 \% e, em Ilustração, 87\%. Na Coleção B, na categoria Retrato as imagens de pessoas 
brancas correspondem a 83\%, em Arte 81 \% e em Ilustração 88\%.

Figura 4. Gráfico da distribuição das imagens por categoria por coleção analisada.
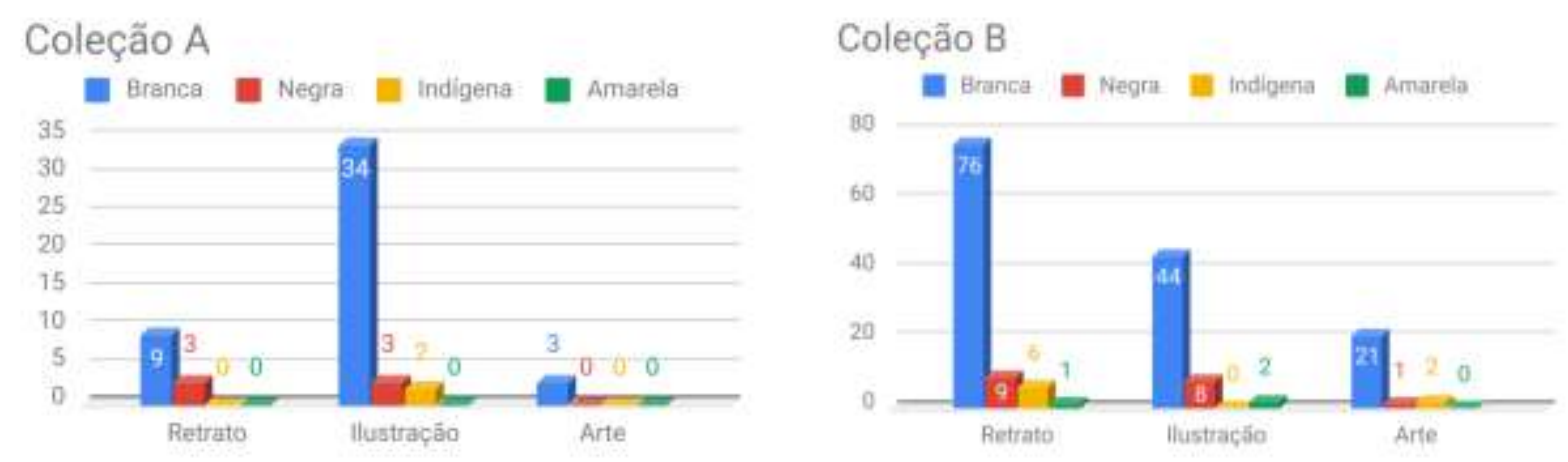

A Tabela 1 mostra a composição da população brasileira, do estado de São Paulo e do município de São Paulo no critério cor ou raça.

Tabela 1. Percentual para a população residente, por cor ou raça, segundo o Censo demográfico de 2010

\begin{tabular}{|l|c|c|c|c|c|}
\hline \multirow{2}{*}{$\begin{array}{c}\text { Brasil, Unidade da Federação e } \\
\text { Município }\end{array}$} & \multicolumn{5}{|c|}{ Cor ou raça (\%) } \\
\cline { 2 - 6 } & Branca & Negra & Indígena & Amarela & Sem declaração \\
\hline Brasil & 47,73 & 50,74 & 0,43 & 1,09 & 0,00 \\
\hline São Paulo & 63,91 & 34,63 & 0,10 & 1,35 & 0,01 \\
\hline São Paulo (SP) & 60,04 & 37,05 & 0,12 & 2,19 & 0,00 \\
\hline
\end{tabular}

Adaptado de: https://sidra.ibge.gov.br/tabela/3175

Se comparada a distribuição étnico-racial dos materiais didáticos analisados com os dados expostos na Tabela 1, observa-se que, apesar dos brancos representarem cerca de 63,91\% da população estadual de São Paulo e 60,04\% da população municipal de São Paulo, eles constituem de 85,2\% na coleção A (caderno estadual) e 82,4\% na coleção B (caderno municipal) das representações humanas nas coleções didáticas de Ciências da Natureza. Estes resultados mostram que presença de pessoas brancas é superestimada nas imagens, em

Revista da ABPN • v. 11, Ed. Especial - Caderno Temático: "Saber-fazer em Ciências \& Tecnologias - Trajetórias Afrodiaspóricas" • dezembro de 2019, p. 90-108 
relação à sua participação na distribuição etnográfica brasileira.

Os negros (pardos e pretos), por sua vez, embora constituam uma parcela expressiva da população estadual e municipal $(34,63 \%$ e $37,05 \%$, respectivamente), têm representatividade muito menor do que se poderia inferir, aproximadamente, $11 \% \mathrm{em}$ ambas as coleções. Assim, observa-se que as coleções didáticas não apresentam, em termos de representatividade, afinidades com a proposta de equidade racial, pois os brancos estão superrepresentados enquanto os negros estão sub-representados.

Dessa forma, constata-se que, por se tratar de um material didático elaborado pelo Poder Público, há deficiência do Estado na promoção formal em igualdade de tratamento conforme expresso na Política Nacional de Promoção da Igualdade Racial (PNPIR):

[...] o Estado tem que redefinir o seu papel no que se refere à prestação dos serviços públicos, de forma a ampliar sua intervenção nos domínios das relações intersubjetivas e privadas, buscando traduzir a igualdade formal em igualdade de oportunidades e tratamento. (BRASIL, 2003, p. 8)

\section{A REPRESENTAÇÃO DE NEGROS E BRANCOS NOS CADERNOS DIDÁTICOS}

Conforme já mostrado, há um desbalanço entre o número de imagens de figuras humanas negras e brancas na coleção A, existem 46 imagens de pessoas brancas e apenas 6 de pessoas negras; na coleção B, 141 imagens são de pessoas brancas e 18 de negras. Porém, é preciso analisar, também, o contexto em que as imagens são apresentadas.

Embora o universo de imagens seja baixo para que se depreendam categorias, considerando as seis imagens de negros da coleção A nota-se que elas se referem a dois grupos (Quadro 3). No grupo 1, há a apresentação do negro no trabalho braçal e, no grupo 2, o negro é apresentado na execução de procedimentos experimentais. Em duas imagens (de um total de seis), a coleção A apresenta o negro executando um trabalho "braçal", reiterando estereótipos por meio de uma representação do negro em função social considerada inferior.

Quadro 3. Exemplo de imagens do negro na coleção A.

Qualificação 1 - Trabalhador "braçal" 2 - Executor de experimento 


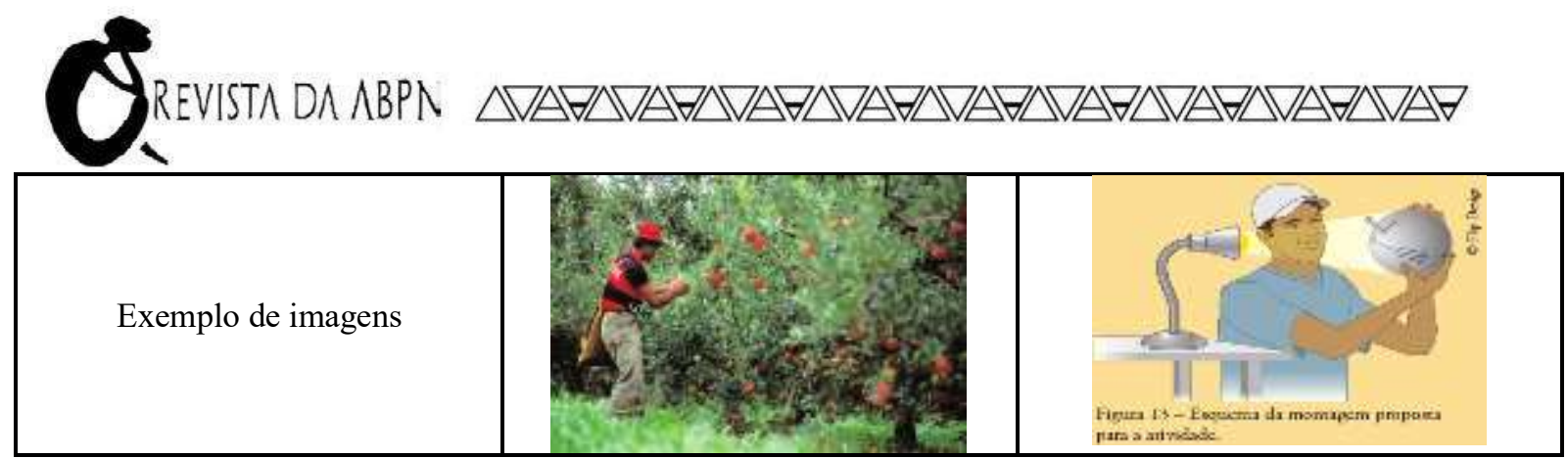

$\mathrm{Na}$ coleção A, em cinco imagens, aparecem oito representações de crianças brincando, sete delas são de crianças brancas. Isso acontece na mesma coleção em que as únicas duas imagens da representação do trabalho socialmente categorizado como inferior retrata figuras negras. Ainda na coleção A, é possível observar uma única representação de trabalho socialmente categorizado como superior, e este é representado por uma pessoa branca.

Já na coleção B, nota-se a existência de três grupos de imagens: o personagem de exercício/quadro ilustrativo, o executor de experimento e a personalidade (Quadro 4), assim, se comparados com a coleção A, verifica-se que há maior diversidade nas escolhas das representações humanas.

Em apenas uma imagem (de um total de 18), a coleção B coloca pessoas negras relacionadas à pobreza, contribuindo para os estereótipos por meio de uma representação do negro em função social considerada inferior. Dessa forma, compreende-se que, em termos de significação das imagens, observa-se que a coleção B, além de apresentar porcentagem menor de representações do negro em função social tida como inferior, as demais representações são mais diversificadas, o que pode contribuir para a construção de uma representação social do negro e da negritude mais positiva.

Quadro 4. Exemplo de imagens do negro na coleção B.

\begin{tabular}{|c|c|c|c|}
\hline Qualificação & $\begin{array}{c}\text { 1 - Personagem de } \\
\text { exercício/quadro ilustrativo }\end{array}$ & 2 - Executor de experimento & 3 - Personalidade \\
\hline $\begin{array}{c}\text { Exemplo de } \\
\text { imagens }\end{array}$ & & & \\
\hline
\end{tabular}


Na coleção B, por se ter alterado o tipo majoritário de imagem de Ilustração para Retrato, pode-se explorar, de maneira mais ampla, a figura do cientista, como Einstein e Pasteur. Das 38 aparições de cientistas/inventores todas são de pessoas brancas. Vale mencionar que, embora a coleção B tenha uma unidade de estudo denominada "Desigualdade de gênero: uma questão biológica ou sociocultural?" de todas as aparições de cientistas/inventores apenas 4 delas são mulheres. A distribuição dessa categoria de imagem reforça a representação do trabalho intelectual como um espaço reservado para homens brancos, já materializado no imaginário da maioria das crianças, como mostra a pesquisa de Rosenthal e Rezende (2017).

Em síntese, com relação à análise das imagens de pessoas brancas, em ambos os cadernos, elas não se encontram exercendo funções sociais tidas como inferiores em nosso contexto social, além de haver uma maior quantidade de qualificações para as funções ilustradas nas imagens. O que chama a atenção é o fato das funções sociais consideradas como superiores (por exemplo, o trabalho intelectual) estarem significativamente mais presentes nas imagens em que se representam pessoas brancas, mas praticamente ausentes nas imagens referentes a negros.

Dessa forma, apesar dos anos que as separam, observa-se que a melhora na qualificação das imagens de pessoas brancas e negras é quase irrelevante, quando se compara a coleção B com a coleção A, persistindo a representação privilegiada da figura da pessoa branca em atividades que remetem ao lazer, à arte e à atividade científica.

\section{CONSIDERAÇÕES FINAIS}

As pesquisas pioneiras de Ana Célia Silva, na década de 80, mostraram que a representação do negro nos livros didáticos das escolas de Ensino Básico, além de rara, ajudava a reforçar estereótipos e a discriminação, invisibilizando seus valores históricos e culturais. A disseminação de representações negativas dos negros para os negros faz com que a depreciação seja naturalizada e a própria criança se sujeite a concepções preconceituosas sobre si, acreditando ser esta a realidade e não uma representação social distorcida sobre o 
mundo. É a partir desse fato que muitas pesquisas começam a voltar-se a aspectos relacionados à autoestima e autorrejeição. Ou seja, a criança tende a não aceitar a si e nem aos seus semelhantes, por haver uma ruptura na sua relação com a própria identidade étnicoracial, que faz com que não queira, deste modo, pertencer a um grupo socialmente inferiorizado.

Neste trabalho, por sua vez, observa-se que as coleções A, publicada em 2009, e B, em 2018, estão aquém do desejável para a representação étnico-racial equânime e que rompa esteriotipias arraigadas na sociedade brasileira. Sendo assim, o presente trabalho contribui para a revelação da questão étnico-racial no Ensino de Ciências mostrando que, mesmo após 15 anos de legislação para a equidade racial, os materiais didáticos para o ensino das Ciências da Natureza ainda reiteram o exercício da ciência como um espaço de homens brancos.

Ao dar atenção para os novos materiais didáticos adotados nas escolas públicas do município e do Estado de São Paulo, defende-se que esses instrumentos pedagógicos não percam os ganhos sociais, em termo de qualidade, daquilo que vem sendo preconizado para os livros didáticos nos editais do Programa Nacional do Livro Didático (PNLD):

\section{PRINCÍPIOS}

$[\ldots]$

1.1. A avaliação das obras didáticas submetidas à inscrição no PNLD 2018 busca garantir a qualidade do material a ser encaminhado à escola [...]. Como parte integrante de suas propostas pedagógicas, as obras didáticas devem contribuir efetivamente para a construção de conceitos, posturas frente ao mundo e à realidade, favorecendo, em todos os sentidos, a compreensão de processos sociais, científicos, culturais e ambientais. Nessa perspectiva, elas devem representar a sociedade na qual se inserem, procurando:

$[\ldots]$

1.1.6. promover positivamente a imagem de afrodescendentes e dos povos do campo, considerando sua participação e protagonismo em diferentes trabalhos, profissões e espaços de poder;

1.1.7. promover positivamente a cultura e história afro-brasileira e dos povos indígenas brasileiros, dando visibilidade aos seus valores, tradições, organizações, conhecimentos, formas de participação social e saberes sociocientíficos, considerando seus direitos e sua participação em diferentes processos históricos que marcaram a construção do Brasil, valorizando as diferenças culturais em nossa sociedade multicultural;

1.1.8. abordar a temática das relações étnico-raciais, do preconceito, da discriminação racial e da violência correlata, visando à construção de uma 
sociedade antirracista, solidária, justa e igualitária. (BRASIL, 2015)

É importante questionar sobre como o ensino de Ciências poderia reverter o quadro de desigualdade racial no Brasil. Os resultados mostram a importância de que os autores considerem o aspecto da representatividade, isto é, fazer com que a distribuição étnico-racial das imagens seja mais próxima da distribuição étnico-racial da sociedade. Mas, ao mesmo tempo, é preciso aproximar as representações imagéticas das pessoas negras daquelas empregadas para as pessoas brancas. Nesse sentido, é preciso que os materiais didáticos de Ciências mostrem que os negros também são dotados de intelecto, contribuindo para a modificação das representações sociais estereotipadas acerca da população negra ainda muito presentes em vários segmentos sociais brasileiros.

Para isso, seria necessário que, futuramente, os autores incorporassem aos materiais didáticos as recentes pesquisas do campo do Ensino de Ciências que acompanham os caminhos trilhados por outras áreas do saber e redesenham aquilo que a estrutura racistaescravagista escreveu sobre os negros (Benite, Silva, Alvino, 2016; Silva, Benite, 2017; Faiad da Silva et al, 2018a; Faiad da Silva, Lima, Maringolo, 2018). É possível, também, que autores de materiais didáticos insiram atividades que incluam a cultura negra (Faiad da Silva et al, 2018b).

Outra forma de remodelar imagens como as apresentadas nas coleções analisadas neste trabalho é trazer a intelectualidade negra da atualidade para os materiais didáticos de Ciências da Natureza. Ou seja, é olhar para os laboratórios de pesquisa científica no Brasil e no mundo e fazer despontar nos materiais didáticos os pesquisadores negros da realidade atual.

Apenas com um redirecionamento e com sensibilidade do olhar, é que se irá promover uma nova representatividade e representação étnico-racial nos materiais didáticos para as Ciências da Natureza.

\section{REFERÊNCIAS}

BARDIN, Laurence. Análise de conteúdo. Lisboa: Edições 70, 1977. 
BRASIL. Lei $n^{\circ} 11.645$, de 10 de março de 2008. Altera a Lei no 9.394, de 20 de dezembro de 1996, modificada pela Lei no 10.639, de 9 de janeiro de 2003, que estabelece as diretrizes e bases da educação nacional, para incluir no currículo oficial da rede de ensino a obrigatoriedade da temática "História e Cultura Afro-Brasileira e Indígena". Diário Oficial da União. 11 mar 2008.

. Ministério da Educação (MEC). EDITAL DE CONVOCAÇÃO 04/2015 - CGPLI. Edital de Convovação para o Processo de Inscrição e Avaliação de Obras Didáticas para o Programa Nacional do Livro Didático PNLD 2018. 2015. Disponível em: $<$ http://portal.mec.gov.br/index.php?option $=$ com_docman\&view=download\&alias=39561-pnld2018-edital-pdf\&category_slug=maio-2016-pdf\&Itemid=30192>. Acessado em: 03 de setembro de 2019

. Política Nacional de Promoção da Igualdade Racial. Brasília, 2003. Disponível em: $<\mathrm{http}$ //bvsms.saude.gov.br/bvs/publicacoes/politica_nacional_promocao_igualdade_racial.pdf $>$. Acessado em: 29 de agosto de 2019.

BENITE, Anna M. Canavarro; SILVA, Juvan Pereira da; ALVINO, Antônio César. Ferro, Ferreiros e Forja: O Ensino de Química pela Lei No 10.639/03. Revista Educação em Foco, v. 21, n. 3, 2016, p. $735-768$.

COELHO NETTO, José Teixeira. Semiótica, informação e comunicação: diagrama da teoria do signo. 6. ed. São Paulo: Perspectiva, 2003.

CORRÊA, Rosa Lydia Teixeira. O livro escolar como fonte de pesquisa em História da Educação. Cadernos Cedes, ano XX, n. 52, 2000, p. 11-24.

FAIAD DA SILVA, Caio Ricardo; LIMA, Gabriela Aparecida de; ALVARENGA, Mateus Augusto Franco de Moraes; REZENDE, Daisy de Brito. África como tema para o ensino de metais: uma proposta de atividade lúdica com narrativas do Pantera Negra. Revista Eletrônica Ludus Scientiae, v. 2, n. 2, 2018, p. 39-55.

FAIAD DA SILVA, Caio Ricardo; LIMA, Gabriela Aparecida de; MARINGOLO, Cátia Cristina Bocaiuva. A análise da canção "Francisco de Oxum" para abordagem em educação das relações étnico-raciais no Ensino de Química. In: CONGRESSO BRASILEIRO DE PESQUISADORES/AS NEGROS/AS, 10., 2018. Uberlândia. Anais [...]. Uberlândia: COPENE, 2018. Disponível em: $<$ https://www.copene2018.eventos.dype.com.br/resources/anais/8/1530536543_ARQUIVO_Trabal hoCompleto-XCOPENE.pdf $>$. Acessado em: 12 outubro de 2018.

FAIAD DA SILVA, Caio Ricardo; SOUZA, Alexandre Araújo; MARINGOLO, Cátia Cristina Bocaiuva; SILVA, Vagner Gonçalves da. A análise do multiculturalismo no currículo de ciências: uma proposta de inserção de cosmogonia iorubá nos conteúdos de Biologia e Astronomia. Revista da Associação Brasileira de Pesquisadores/as Negros/as (ABPN), v. 10, n. Ed. Especia, 2018, p. 381408.

LAJOLO, Marisa. Livro didático: um (quase) manual do usuário. Em Aberto, v. 16, n. 69, 1996, p. 39.

LOPES, Mario Olavo da Silva. Representação Étnico-Racial nos livros didáticos de Ciências da 
Natureza. Dissertação (Mestrado em Educação em Ciências: Química da Vida e Saúde). Instituto de Ciências Básicas da Saúde, Universidade Federal do Rio Grande do Sul, Porto Alegre, 2016.

MAIA, Juliana de Oliveira; VILLANI, Alberto. A relação de professores de Química com o livro didático e o caderno do professor. Revista Electrónica de Enseñanza de las Ciencias, v. 15, n. 1, 2016, p. 121-146.

MAIMONE, Giovana Deliberali; GRACIOSO, Luciana de Souza. Representação temática de imagens: perspectivas metodológicas. Informação \& Informação, v. 12, n. 1, 2007, p. 130-141.

MATTE JÚNIOR, Alexandre Aloys; ALVES, Darlã de; GEVEHR, Daniel Luciano. Representação da etnia negra nos livros didáticos: o papel social da figura do negro no material de apoio pedagógico da educação básica. Revista Acadêmica Licencia\&acturas, v. 5, n. 1, 2017, p. 40-47.

MEGID NETO, Jorge; FRACALANZA, Hilário. O livro didático de ciências: problemas e soluções. Ciência \& Educação, v. 9, n. 2, 2003, p. 147-157.

MUNANGA, Kabengele; GOMES, Nilma Lino. O negro do Brasil de hoje. 2ed. São Paulo: Global, 2016.

RIBEIRO, Giselle Rodrigues. O afro-brasileiro e sua representação no livro didático de língua materna. Trabalhos em Linguística Aplicada, v. 49, n. 1, p. 101-113, 2010.

ROSENTHAL, Renata; REZENDE, Daisy de Brito. Mulheres cientistas: um estudo sobre os estereótipos de gênero das crianças acerca de cientistas. In: SEMINÁRIO INTERNACIONAL FAZENDO GÊNERO, 11.; WOMEN'S WORLDS CONGRESS, 13. 2017. Florianópolis. Anais [...]. Florianópolis: IEG. 2017. p. 2643-2655. Disponível em:

$<$ http://www.wwc2017.eventos.dype.com.br/resources/anais/1498780727_ARQUIVO_Trabalhoco mpletoRenataRosenthal.pdf $>$. Acesso em: 15 março de 2018.

SANTOS, Wellington Oliveira dos. Espaços de negros e brancos em livros didáticos de Geografia do estado do Paraná, Brasil. Ciência \& Educação, v. 19, n. 4, 2013, p. 1027-1044.

SÃO PAULO (Estado). Secretaria da Educação. Caderno do aluno: ciências, ensino fundamental 5a-8a série, volume 1-4. São Paulo: SEE, 2009.

SÃO PAULO (SP). Secretaria Municipal da Educação. Caderno da cidade: saberes e aprendizagens: Ciências Naturais - $6^{\circ}-9^{\circ}$ ano, volume 1. São Paulo: SME/COPED, 2018.

SILVA, Ana Célia. A representação social do negro no livro didático: o que mudou? por que mudou? . Salvador: EDUFBA, 2011.

SILVA, Ana Célia. As transformações da representação social do negro no livro didático e seus determinantes. In: REUNIÃO ANUAL DA ASSOCIAÇÃO NACIONAL DA PÓS-GRADUAÇÃO E PESQUISA EM EDUCAÇÃO, 22., 1999. Caxambu. Anais [...]. Caxambu: ANPEd. Disponível em: $\quad<$ http://www.portcom.intercom.org.br/pdfs/2a80cecae02ccf0480b55db2e4f61cf6.PDF>. Acessado em: 03 de setembro de 2019 


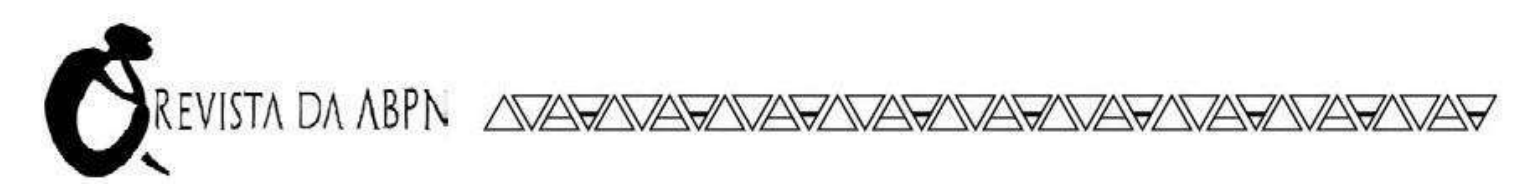

SILVA, Juvan Pereira da; BENITE, Anna Maria Canavarro. Ouro, níquel, congos e a diáspora africana em Goiás: a lei 10639 no ensino de Química. Revista da Associação Brasileira de Pesquisadores/as Negros/as (ABPN), v. 9, n. 22, 2017, p. 273-302.

SILVÉRIO, Florença Freitas. A representação social do corpo humano em livros didáticos de biologia. Monografia (Bacharelado em Ciências Biológicas) - Faculdade de Filosofia, Ciências e Letras. Universidade de São Paulo. Ribeirão Preto. 2016.

TEIXEIRA, Rozana. A representação social da branquidade em livros didáticos de História e Língua Portuguesa. In: CONGRESSO NACIONAL DE EDUCAÇÃO, 10.; SIMPÓSIO INTERNACIONAL DE REPRESENTAÇÕES SOCIAIS, SUBJETIVIDADE E EDUCAÇÃO, 1., 2011. Curitiba. Anais [...]. Curitiba: EDUCERE. 2011, p. 2643-2655. Disponível em:

$<$ https://educere.bruc.com.br/CD2011/pdf/4321_2683.pdfv>. Acesso em: 15 março de 2018.

Recebido em: 30/09/2019

Aceito em: $30 / 11 / 2019$

Revista da ABPN • v. 11, Ed. Especial - Caderno Temático: "Saber-fazer em Ciências \& Tecnologias - Trajetórias Afrodiaspóricas" • dezembro de 2019, p. 90-108 